\title{
Perangkat Project-Based Learning berbantuan ICT: Optimalisasi Kemampuan Pemecahan Masalah dan Kecemasan Matematis Siswa
}

\author{
Asep Amam ${ }^{1^{*}}$, Lilis Lismayanti ${ }^{2}$ \\ ${ }^{1}$ Pendidikan Matematika, Universitas Galuh, Ciamis, Indonesia; ${ }^{1 *}$ asepamam85@gmail.com \\ ${ }^{2}$ Keperawatan, STIKES Muhammadiyah Ciamis, Indonesia; lismayantililis@yahoo.com
}

Info Artikel: Dikirim: 16 September 2020; Direvisi: 21 September 2020; Diterima: 24 September 2020.

Cara sitasi: Amam, A., \& Lismayanti, L. (2020). Perangkat Project-Based Learning berbantuan ICT: Optimalisasi Kemampuan Pemecahan Masalah dan Kecemasan Matematis Siswa. JNPM (Jurnal Nasional Pendidikan Matematika) 4(2), 351-362.

\begin{abstract}
Abstrak. Kemampuan pemecahan masalah dan kecemasan matematis merupakan penyebab utama prestasi matematika siswa di indonesia merosot, baik prestasi UNBK maupun prestasi internasional setingkat PISA dan TIMMS. Tujuan penelitian ini adalah mengembangkan perangkat Project-Based Learning (PjBL) berbantuan ICT yang dapat mengoptimalkan kemampuan pemecahan masalah dan mengelola tingkat kecemasan matematis siswa. Metode menggunakan pengembangan dengan menggunakan model Analysis, Design, Developement, Implementation dan Evaluation (ADDIE). Hasil menunjukan bahwa perangkat yang dikembangkan valid. Sehingga perangkat ini dapat digunakan dalam pembelajaran matematika.
\end{abstract}

Kata Kunci: Project-Based Learning, Pemecahan Masalah Matematis, Kecemasan Matematis.

Abstract. The problem-solving ability and mathematical anxiety is the main cause of the decline in mathematics achievement of students in Indonesia, both national achievement test and international achievements at the level of PISA and TIMMS. The purpose of this research is to develop Project-Based Learning (PjBL) sets with ICT-assisted that can optimize problem-solving abilities and manage students' mathematical anxiety levels. The method uses development using the Analysis, Design, Development, Implementation and Evaluation (ADDIE) model. The results showed that the developed was valid. So that teaching and learning sets can be used in mathematics learning.

Keywords: Project-Based Learning, Mathematical Problem Solving, Mathematical Anxiety.

\section{Pendahuluan}

Ilmu matematika memiliki karakteristik abstak, diperlukan media untuk memudahkan siswa memahami matematika dalam pembelajaran, salah satunya dengan penggunaan teknologi. Penggunaan ICT dalam pembelajaran 
matematika memiliki manfaat diantaranya menjembatani kesenjangan antara konsep-konsep abstrak dan pengalaman kongkrit (Yee \& Hoe, 2009). Tujuan matematika diajarkan pada semua jenjang pendidikan dasar dan menengah salah satunya adalah agar siswa mampu memecahkan masalah matematis. Fakta empiris menunjukan hal yang tidak sejalan dengan harapan pemerintah terbukti dengan prestasi matematika UNBK 2017 sekitar $70 \%$ nilai matematika di sekolah masih dibawah 55 (Asih, 2019). Hal tersebut menunjukan bahwa kemampuan matematis siswa masih rendah. Selain itu penilaian internasional pada studi PISA menunjukan reputasi siswa Indonesia pada pelajaran matematika masih rendah terlihat pada tabel 1 (OECD, 2003; OECD, 2006; OECD, 2009; Stacey, 2011; OECD, 2016; Harususilo, 2019).

Tabel 1. Skor, Rata-Rata dan Peringkat Kemampuan Matematis Siswa Indonesia

\begin{tabular}{cccc}
\hline Tahun & Skor & $\begin{array}{c}\text { Rata-rata } \\
\text { OECD }\end{array}$ & Peringkat \\
\hline 2000 & 367 & 500 & 39 dari 41 negara \\
2003 & 360 & 500 & 38 dari 40 negara \\
2006 & 391 & 500 & 50 dari 57 negara \\
2009 & 371 & 496 & 61 dari 65 negara \\
2012 & 375 & 494 & 62 dari 65 negara \\
2015 & 386 & 490 & 63 dari 70 negara \\
2018 & 379 & 489 & 72 dari 78 negara \\
\hline
\end{tabular}

Salah satu penghambat keberhasilan siswa dalam memecahkan masalah matematika adalah kecemasan (Amam, Darhim, Fatimah, \& Noto, 2019). Kecemasan matematik merupakan salah satu hambatan yang sangat serius dalam pendidikan, serta berkembang pada anak-anak dan remaja dalam lingkungan sekolah (Warren, Rambow, Pascarella, Michel, Schultz, \& Marcus, 2005). Oleh sebab itu diperlukan sebuah model pembelajaran yang dapat menekan terjadinya kecemasan pada diri siswa pada saat pemebelajaran maupun pada saat tes matematika berlangsung agar kemampuan pemecahan masalah matematis siswa dapat berkembang dengan optimal.

Project-Based Learning (PjBL) adalah sebuah model pembelajaran yang inovatif, yang menekankan belajar kontekstual melalui kegiatan-kegiatan yang kompleks (Cord, 2001; Thomas, Mergendoller, \& Michaelson, 1999). PjBL berfokus pada konsep-konsep dan prinsip-prinsip utama (central) dari suatu disiplin, melibatkan siswa dalam kegiatan pemecahan masalah dan tugastugas bermakna lainnya, memberi peluang siswa belajar secara otonom, mengkonstruk belajar mereka sendiri, dan puncaknya menghasilkan produk karya siswa bernilai dan realistik (Okudan \& Rzasa, 2006). Kegiatan PjBL menurut Rosenfeld (Rosenfeld \& Ben-Hur, 2001) terdiri dari: (1) membuat pertanyaan yang akan dijadikan proyek, (2) memilih pertanyaan utama atau 
menentukan proyek, (3) membaca dan mencari materi yang relevan dengan masalah, (4) merancang masalah, (5) merancang/metode yang tepat dalam memecahkan masalah, (6) menulis proyek proposal, (7) implementasi dan membuat dokumen tugas, (8) analisis data dan membuat simpulan, (9) membuat laporan final, (10) mempresentasikan proyek final.

Dalam upaya memecahkan masalah matematis siswa pada saat ini keberadaan ICT sangat diperlukan terutama pada tahap mencari materi yang relevan untuk pencarian sumber yaitu dengan menggunakan media internet dan merancang metode ataupun implementasi model dengan menggunakan media software matematika. Sejalan dengan pendapat Young mengungkapkan bahwa ICT mengacu pada teknologi yang menggunakan perangkat lunak komputer atau internet. Selain itu Penggunaan ICT dalam pembelajaran matematika menurut Young dapat menggunakan salah satu mode, yaitu: (1) tutor mode; (2) tool mode; (3) tutte mode dan (4) co-learner mode (Amam, 2013). Adapun jika menurut kusumah pembelajaran berbantuan computer dapat dilakukan dengan cara: Latihan dan Praktek (Drill and Practice), Tutorial, Simulasi, Penemuan Interaktif, Permainan (game), Presentasi atau Demonstrasi, Komunikasi, Tes, Sumber informasi dan Pemecahan masalah (Kusumah, 2017).

Berikut ini beberapa pernyataan para pakar dan peneliti yang mengarah pada pentingnya PjBL, ICT, pemecahan masalah dan kecemasan matematis diantaranya adalah: Proyek merupakan tugas kompleks yang melibatkan siswa dalam desain pemecahan masalah, pengambilan keputusan, dan kegiatan investigasi. Siswa bekerja secara mandiri dengan waktu yang lebih panjang, dan mempersiapkan produk atau presentasi realistis. Selain itu proyek dapat meningkatkan kreatifitas dalam pemecahan masalah dan PjBL merupakan model pembelajaran yang berfokus pada konsep, melibatkan siswa pada pemecahan masalah sebagai tugas yang bermakna, memungkinkan siswa bekerja mandiri untuk membangun pengetahuannya dan berpusat pada realistik sebagai sebuah karya (Mergendoller \& Thomas, 2000); (Okudan \& Rzasa, 2006); (Rosenfeld \& Ben-Hur, 2001).

PjBL erat sekali kaitannya dengan pemecahan masalah matematis. Selain itu proyek juga erat kaitanya dengan ICT seperti yang diungkapkan (Bodnar \& Hazy, 1999) bahwa penerapan proyek menggunakan ICT dapat menjembatani antara teori dan praktek. Pendapat lain juga mengungkapkan bahwa menggunakan teknologi sebagai alat untuk mengurangi kecemasan matematika (Sun \& Pyzdrowski, 2009). Dari beberapa pendapat tersebut peneliti berusaha mendesain dalam penelitian ini untuk merancang instrumen 
yang mengkolaborasikan ICT pada sintaks PjBL sehingga sintak dan instrumen yang digunakan dapat mengoptimalkan kemampuan pemecahan masalah matematis siswa dan dapat mengendalikan tingkat kecemasan matematis siswa dengan baik. Tujuan penelitian ini adalah mengembangkan sintaks dan perangkat PjBL berbantuan ICT yang dapat mengoptimalkan kemampuan pemecahan masalah dan mengelola tingkat kecemasan matematis siswa.

\section{Metode}

Penelitian ini menggunakan pengambangan dengan model Analysis, Design, Development or Production, Implementation or Delivery and Evaluations (ADDIE) (Molenda, 2003). Tahapan Analysis dan Design telah dilakukan pada penelitian sebelumnya. Sedangkan tahapan Development or Productions dilakukan dengan langkah-langkah pada tabel 2.

Tabel 2. Proses Pengembangan Model PjBL berbantuan ICT

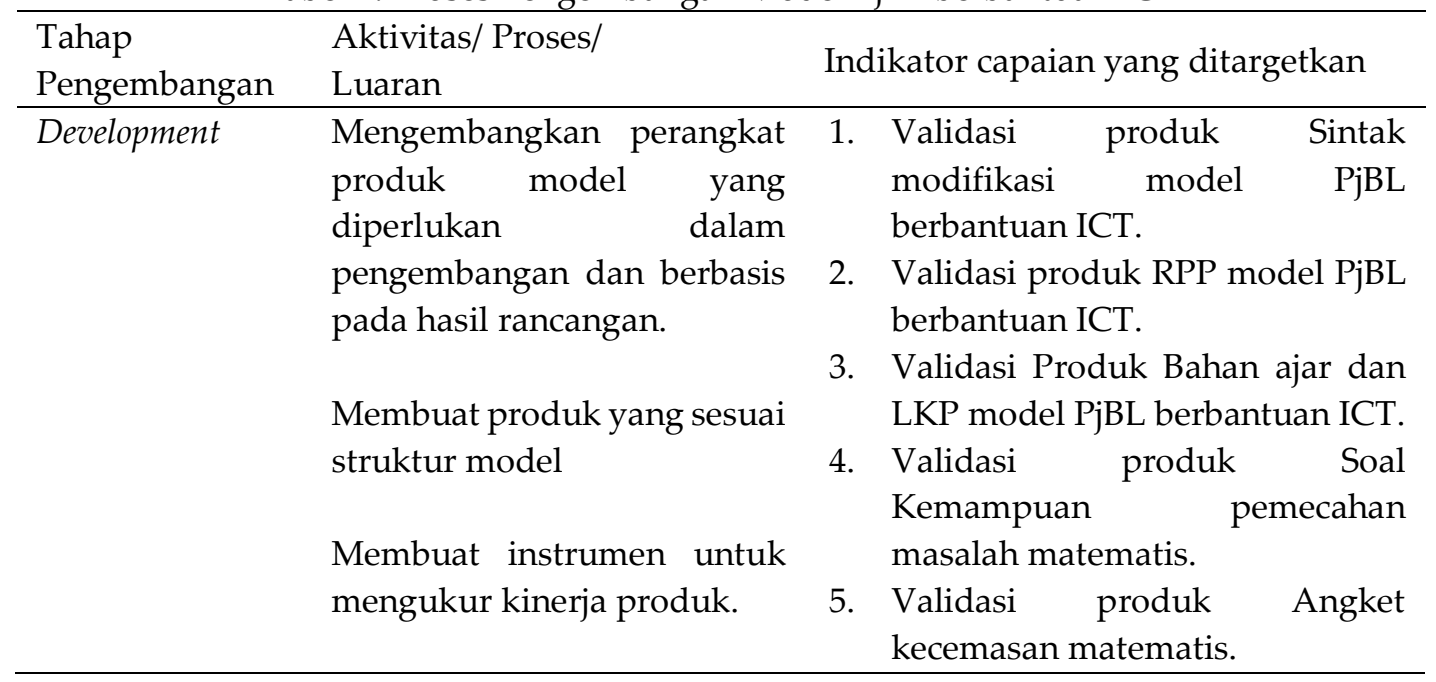

Penelitian ini melibatkan lima validator ahli dalam proses pengembangan model dan perangkat. Selain ahli juga melibatkan subjek uji coba empiris yaitu siswa kelas IX pada salah satu SMPN di kabupaten Ciamis sebanyak 16 Siswa untuk uji soal kemampuan pemecahan masalah matematis. Uji coba soal tes ini bertujuan untuk mengetahui kualitas butir soal yang meliputi validitas, reliabilitas, daya pembeda, dan indeks kesukaran yang akan digunakan dalam penelitian. Analisis data dilakukan secara deskriptif.

\section{Hasil dan Pembahasan}

\section{Hasil Validasi produk modifikasi Sintak model PjBL berbantuan ICT}

Penelitian ini memodifikasi sintak PjBL yang sudah ada sebelumnya yaitu sintak PjBL Doppelt (Doppelt, 2003b), sintak PjBL Lucas (Larmer, 2014) dan sintaks PjBL Laboy (Laboy-Rush, 2010). Hal tersebut dilakukan dengan 
pertimbangan sintaks PjBL yang ada belum mengakomodir secara spesifik untuk mengoptimalkan kemampuan pemecahan masalah matematis dan mengelola tingkat kecemasan siswa. Sehingga sintak yang sudah ada dimodifikasi dengan mengaitkan secara langsung dengan penggunaan ICT. Hal tersebut dilakukan karena penggunaan ICT dapat menurunkan kadar tingkat kecemasan siswa baik pada pembelajaran maupun saat tes matematika berlangsung (Sun \& Pyzdrowski, 2009).

Selain itu pengembangan ini didasarkan pada beberapa pendapat ahli yang menyatakan bahwa pembelajaran berbasis proyek adalah suatu pendekatan pendidikan yang efektif yang berfokus pada kreativitas berpikir, pemecahan masalah, dan interaksi antara siswa dengan kawan sebaya mereka untuk menciptakan dan menggunakan pengetahuan baru. Khususnya dilakukan dalam konteks pembelajaran aktif, dialog ilmiah dengan supervisor yang aktif sebagai peneliti (Berenfeld, 1996); (Marchaim, 2001); (Asan, 2005). Berdasarkan pendapat-pendapat tersebut, PjBL merupakan model pembelajaran yang dikembangkan berdasarkan paham pembelajaran konstruktivis yang menuntut peserta didik menyusun sendiri pengetahuannya (Doppelt, 2003a).

Adapun sintak PjBL berbantuan ICT yang dikembangkan pada penelitian ini dianalisis dan dikembangkan dengan berdasar pada sintak PjBL yang sudah ada, indikator kemampuan pemecahan masalah matematis dan kecemasan matematis siswa.

Tabel 3.Sintak PJBL berbantuan ICT hasil pengembangan

\begin{tabular}{|c|c|c|c|}
\hline PJBL Doppelt & PJBL Lucas & $\begin{array}{c}\text { PJBL } \\
\text { Laboy-rush }\end{array}$ & $\begin{array}{c}\text { PJBL berbantuan } \\
\text { ICT }\end{array}$ \\
\hline 1. Design purpose & 1. Start with essential & 1. Reflection & 1. Refleksi masalah \\
\hline 2. Field of inquiry & question & 2. Research & kontekstual \\
\hline 3. Solution & 2. Design project & 3. Discovery & 2. Riset menggunakan \\
\hline alternatives & 3. Create schedule & 4. Application & media teknologi \\
\hline $\begin{array}{l}\text { 4. Choosing the } \\
\text { preferred }\end{array}$ & $\begin{array}{l}\text { 4. Monitoring the } \\
\text { students and progress }\end{array}$ & 5. Communication & $\begin{array}{l}\text { 3. Penemuan } \\
\text { menggunakan }\end{array}$ \\
\hline 5. Operation steps & of project & & software \\
\hline \multirow[t]{3}{*}{ 6. Evaluation } & 5. Assess the outcome & & 4. Aplikasi \\
\hline & $\begin{array}{l}\text { 7. Evaluation the } \\
\text { experience }\end{array}$ & & $\begin{array}{l}\text { menggunakan } \\
\text { software }\end{array}$ \\
\hline & & & $\begin{array}{l}\text { 5. Komunikasi } \\
\text { menggunakan } \\
\text { media teknologi }\end{array}$ \\
\hline
\end{tabular}

Tabel 3 menunjukkan proses dan hasil pengembangan sintaks PjBL. Sebelum melakukan validasi ahli, tahap analisis dan desain sudah dilaksanakan pada 
penelitian sebelumnya sehingga menghasilkan sintak yang sudah dimodipikasi dengan mempertimbangkan sintak PjBL yang sudah ada, indikator kemampuan pemecahan masalah matematis dan indikator kecemasan matematis. Validasi yang dilakukan adalah validasi isi dan muka oleh lima ahli dilakukan dengan menggunakan instrumen angket, wawancara dan diskusi. Instrumen isi yaitu memahamkan validator terhadap sintak PjBL yang sudah ada dan rancangan sintak hasil modifikasi, indikator kemampuan pemecahan masalah matematis dan indikator kecemasan matematis.

Hasil uji validasi terhadap sintak baru dengan cochran pada muka dan isi didapatkan nilai signifikansi 0,58 dan 0,67, artinya baik secara muka maupun isi semua item sudah valid dan dapat digunakan. Pada saat proses validasi muka dan isi mendapatkan beberapa saran dan komentar dari validator diantaranya: Pemilihan kata pada muka sintak sebaiknya menggunakan istilah yang berbeda dari sintak yang sudah ada, secara isi tidak boleh menimbulkan multi tafsir terhadap sintak yang dimodifikasi dan sintak harus focus pada indikator kemampuan pemecahan masalah baik tersurat ataupun tersirat secara langsung pada sintak yang dimodifikasi. Selain melalui angket proses diskusi dan revisi dilaksanakan sehingga dapat menghubungkan indikator kemampuan pemecahan masalah matematis, kecemasan matematis dan PJBL-ICT. Setelah proses revisi dan penyesuaian maka didapatkan sintak PJBL berbantuan ICT yang dapat mengoptimalkan kemampuan pemecahan masalah dan mengelola kecemasan matematis siswa pada tabel 3.

\section{Hasil Validasi produk RPP model PjBL berbantuan ICT}

Penilaian lima validator terhadap Rencana Pelaksanaan Pembelajaran (RPP) didasarkan pada indikator-indikator yang termuat dalam lembar validasi RPP sebanyak 15 item. RPP PjBL berbantuan ICT yang dikembangkan pada penelitian ini disusun berdasarkan sintak PjBL berbantuan ICT yaitu refleksi masalah kontekstual, riset menggunakan media teknologi internet, penemuan menggunakan software, aplikasi menggunakan software, komunikasi menggunakan media teknologi. Dengan pengembangan RPP menitikberatkan pada aktifitas siswa selama proyek selalu mengoptimalkan penggunaan teknologi pada saat pemecahan masalah berlangsung. Sesuai dengan pendapat (Sun \& Pyzdrowski, 2009) agar penggunaan teknologi pada saat aktifitas pembelajaran matematika dapat menurunkan tingkat kecemasan matematis siswa. Hasil penilaian validator terhadap RPP, berdasarkan uji Cochran dapat dilihat pada tabel 4. 
Tabel 4. Validitas RPP

\begin{tabular}{llll}
\hline No & RPP & Nilai Sig & Keterangan \\
\hline 1 & RPP 1 & 0,589 & Valid \\
2 & RPP 2 & 0,736 & Valid \\
3 & RPP 3 & 0,504 & Valid \\
4 & RPP 4 & 0,893 & Valid \\
5 & RPP 5 & 0,831 & Valid \\
\hline
\end{tabular}

Tabel 4 menunjukkan bahwa secara umum pandangan validator terhadap lima RPP yang didesain mendapatkan penilaian baik dan tidak terdapat perbedaan penilaian kelima validator terhadap RPP model PjBL berbantuan ICT pada kategori valid dengan kata lain semua RPP yang sudah didesain layak digunakan untuk optimalisasi kemampuan pemecahan masalah dan managemen kecemasan matematis siswa. Dengan catatan hanya pada penggunaan teknologi harus dioptimalkan dengan baik.

\section{Hasil Validasi produk Bahan ajar dan LKP model PjBL berbantuan ICT}

Bahan ajar dan Lembar Kerja Proyek (LKP) yang dikembangkan dalam penelitian ini lebih menitikberatkan pada penyajian masalah kontekstual pada bahan ajar dan LKP, Soal atau masalah harus komplek dan bisa diselesaikan dengan bantuan software matematika. Penilaian lima validator terhadap bahan ajar dan lembar kerja proyek didasarkan pada indikator-indikator yang termuat dalam Lembar Validasi bahan ajar yang diberikan sebanyak 6 item pertanyaan, Hasil uji cochran didapat seperti pada tabel 5. Secara umum penilaian validator baik terhadap bahan ajar dan LKP yang telah dikembangkan, hanya ada beberapa saran dan komentar tertulis diantaranya, penggunaan masalah kontekstual harus sesuai dengan pengalaman dan jenjang sekolah siswa juga soal yang diberikan pada LKP harus bisa terselesaikan oleh software matematika yang sudah dikenal oleh siswa.

Tabel 5. Validitas Bahan Ajar dan LKP

\begin{tabular}{llll}
\hline No & Bahan Ajar \& LKP & Nilai Sig & Keterangan \\
\hline 1 & Bahan Ajar \& LKP 1 & 0,831 & Valid \\
2 & Bahan Ajar \& LKP 2 & 0,558 & Valid \\
3 & Bahan Ajar \& LKP 3 & 0,593 & Valid \\
4 & Bahan Ajar \& LKP 4 & 0,506 & Valid \\
5 & Bahan Ajar \& LKP 5 & 0,645 & Valid \\
\hline
\end{tabular}

Tabel 5 menunjukkan bahwa secara umum dapat disimpulkan tidak terdapat perbedaan pandangan validator terhadap kualitas bahan ajar dan lembar kerja proyek yang digunakan dalam penelitian sehingga layak/valid digunakan untuk optimalisasi kemampuan pemecahan masalah dan managemen kecemasan matematis siswa. 


\section{Hasil Validasi Soal Kemampuan pemecahan masalah matematis (KPMM)}

Pengembangan soal KPMM siswa didasarkan pada kisi-kisi dan indikator kemampuan pemecahan masalah matematis meliputi: memahami masalah, merencanakan masalah, melakukan perhitungan dan pengecekan kembali (Amam, 2017). Masalah dalam pembelajaran matematika menurut (Ruseffendi, 2006) mengemukakan bahwa suatu persoalan merupakan masalah bagi seseorang bila persoalan itu tidak dikenalnya, dan orang tersebut mempunyai keinginan untuk menyelesaikannya, terlepas mengetahui sampai akhir atau tidak kepada jawaban masalah tersebut. Bell (Bell, 1978) menyatakan bahwa suatu situasi merupakan suatu masalah bagi seseorang, jika ia sadar bahwa itu ada, mengenali kegiatan yang diperlukan, ingin atau butuh untuk mengerjakannya, dan tidak secara seketika dapat menyelesaikan situasi atau masalah tersebut. Dalam usaha mencapai kemampuan pemecahan masalah matematis yang baik, siswa harus fokus pada 3 hal berikut (Schoenfeld, 1992): Mencari solusi, tidak hanya mengingat prosedur; Mengeksplor pola, tidak hanya mengingat rumus; dan Merumuskan konjektur, tidak hanya melakukan latihan. Proses pengembangan soal KPMM inipun sudah didasarkan pada beberapa pandangan para ahli yang sudah di kemukakan di atas.

Pengembangan soal tes KPMM peneliti melakukan proses validasi dari para pakar yang meliputi validasi isi dan validasi muka. Validasi isi bertujuan untuk mengetahui ketepatan suatu alat evaluasi ditinjau dari segi materi yang dievaluasikan, ketepatan tes untuk mengukur aspek dan indikator yang telah ditentukan, dan kebenaran konsep dari materi yang disajikan dalam instrumen tes (Suherman, \& Kusumah, 1990). Oleh karena itu, penilaian validator terhadap tes KPMM berdasarkan pada aspek muka yaitu: Menganggap item tersebut telah memenuhi kejelasan dari segi bahasa/redaksional, dan atau kejelasan dari segi gambar/refresentasi yang diberikan dan aspek isi yaitu: Mengagap item tersebut telah sesuai dengan Materi pokok, Tujuan yang ingin dicapai, Aspek kemampuan yang diukur, Indikator kemampuan yang diukur dan tingkat kesukaran untuk siswa SMP. Hasil uji validasi dengan cochran pada muka KPMM dan isi KPMM didapatkan nilai signifikansi 0,558 dan 0,663, artinya baik secara muka maupun isi semua item soal KPMM valid dan dapat digunakan.

Adapun uji validitas empiris terhadap soal KPMM juga dilakukan terhadap 19 siswa kelas IX SMP yang ada dikabupaten ciamis dengan sebaran siswa dari kemampuan awal matematis yang heterogen dan sudah mendapatkan materi yang terdapat pada soal yaitu materi persamaan garis lurus dan 
persamaan linier dua variable. Dengan proporsi kemampuan awal matematis $30 \%$ rendah, $40 \%$ sedang dan 30\% Tinggi. Hasil uji empiris disajikan pada tabel 6 .

Tabel 6. Rekapitulasi Hasil Uji Coba Tes KPMM

\begin{tabular}{lllllllll}
\hline No. & \multicolumn{2}{l}{ Validitas } & \multicolumn{2}{c}{ Reliabilitas } & \multicolumn{2}{c}{ Daya Pembeda } & \multicolumn{2}{c}{ Indeks Kesukaran } \\
Soal & $\mathrm{r}_{\mathrm{xy}}$ & \multicolumn{2}{c}{ Interpretasi $\mathrm{r}_{11}$} & \multicolumn{2}{c}{ Interpretasi Indeks } & Interpretasi & Indeks & Interpretasi \\
\hline 1. & 0,467 & Sedang & & & 0,415 & Baik & 0,3754 & Sedang \\
2. & 0,417 & Sedang & \multirow{2}{*}{0,48} & Sedang & 0,2250 & Cukup & 0,4625 & Sedang \\
3. & 0,689 & Tinggi & & & 0,4750 & Baik & 0,3875 & Sedang \\
4. & 0,775 & Tinggi & & & 0,5500 & Baik & 0,4000 & Sedang \\
\hline
\end{tabular}

Tabel 6 menunjukkan bahwa hasil validasi soal secara empiris terhadap siswa SMP valid dan dapat digunakan untuk mengukur kemampuan pemecahan masalah matematis siswa.

\section{Hasil Validasi Angket kecemasan matematis siswa}

Angket kecemasan matematis (KM) yang dikembangkan dalam penelitian ini meliputi indikator sikap, somatik dan kognitif (Amam, Darhim, Fatimah, \& Noto, 2019). Furner dan Duffy (Sun \& Pyzdrowski, 2009) menyatakan bahwa kecemasan matematika berhubungan dengan bidang afektif dan kognitif. Bidang afektif terkait pada kondisi emosi yang berhubungan dengan rasa takut dan khawatir terhadap masa depan, dan bidang kognitif berhubungan pada ketidakmampuan dalam melakukan tugas matematika tertentu. Sementara itu, Bursal dan Paznokas (Gresham, 2010) mengatakan bahwa kecemasan matematika merupakan keadaan tidak berdaya dan panik ketika diminta untuk mengerjakan tugas matematis. Furner dan Berman (Gresham, 2010) juga menggambarkan kecemasan matematika sebagai sindrom "saya tidak bisa", kecemasan matematika dapat disebabkan dari pengalaman matematika yang memalukan atau karena ketidakmampuan dalam menerapkan pemahaman dan penggunaan konsep matematis. Siswa mungkin mengalami kecemasan matematika karena mereka tidak pernah mengalami keberhasilan di kelas matematika (Smith, Smoll, Cumming, \& Grossbard, 2006)

Skala KM dalam penelitian ini digunakan untuk mengungkap sikap dan kebiasaan siswa pada aspek kecemasan yaitu pada saat pembelajaran dan saat mengikuti tes dengan indikator kecemasan: sikap, somatic dan kognitif. Skala ini dibuat dengan berpedoman pada bentuk skala Likert dengan lima pilihan jawaban alternatif yang mengarah pada frekuensi yang ditulis Tidak setuju (1), agak tidak setuju (2), netral/kadang-kadang (3), agak setuju(4 )dan setuju(5). Jenis butir pernyataan dalam skala ini terdiri dari butir-butir pernyataan 
negatif. Sebaran jumlah butir pernyataan yang digunakan dalam penelitian berdasarkan aspek-aspek kecemasan matematis disajikan pada Tabel 7.

Tabel 7. Rekapitulasi Banyaknya Butir Pernyataan untuk Setiap Aspek KM

\begin{tabular}{lll}
\hline Indikator situasi & Indikator kondisi & Nomor Item \\
\hline Pembelajaran Matematika & Sikap & $1,3,6$ \\
& Somatic & 2,4 \\
& Kognitif & 9 \\
Tes Matematika & Kognitif & $5,7,8,10$ \\
\hline
\end{tabular}

Tabel 7 menunjukkan hasil uji validasi dengan cochran pada muka dan isi KM pernyataan pada angket, didapatkan nilai signifikansi berturut-turut yaitu 0,539 dan 0,683 , artinya baik secara muka maupun isi semua item pernyataan pada KM valid dan dapat digunakan.

\section{Simpulan}

Hasil pengembangan perangkat PjBL berbantuan ICT adalah valid sehingga dapat mengoptimalkan kemampuan pemecahan dan mengelola kecemasan matematis siswa. Perangkat terdiri dari sintak PjBL berbantuan ICT dimodifikasi, RPP, bahan ajar, LKP, soal kemampuan pemecahan masalah matematis, dan angket kecemasan matematis. Guru dapat menggunakan perangkat ini untuk mengoptimalkan kemampuan pemecahan masalah matematis, dan angket kecemasan matematis siswa.

\section{Ucapan Terima Kasih}

Terima kasih kepada Direktorat Riset dan Pengabdian Masyarakat, Kemenristekdikti yang telah mendanai penelitian, LPPM Universitas Galuh yang sudah menjadi fasilitator pendanaan penelitian, SMPN 2 dan MTsN 13 Ciamis yang sudah bersedia menjadi subjek penelitian, dan para validator diantaranya: Dr. Marwia Tamrin Bakar (Universitas Khairun, Ternate); Dr. Yulyanti Harisman (Universitas Negeri Padang); Dr. Budi Mulyono (Universitas Sriwijaya); Muchamad Subali Noto (Universitas Swadaya Gunung Djati, Cirebon) dan Lukman Harun (Universitas PGRI Semarang).

\section{Daftar Pustaka}

Amam, A. (2013). Pengaruh Pembelajaran Matematika Berbasis Ict Terhadap Kemampuan Pemahaman Dan Pemecahan Masalah Matematis Siswa Smp. Bandung: Doctoral dissertation, Universitas Pendidikan Indonesia.

Amam, A., Darhim, D., Fatimah, S., \& Noto, M. S. (2019). Math anxiety performance of the 8th grade students of junior high school. Journal of Physics: Conference Series, 1157(4). https://doi.org/10.1088/1742-6596/1157/4/042099

Amam, Asep. (2017). Penilaian Kemampuan Pemecahan Masalah Matematis Siswa Smp. TEOREMA: Teori Dan Riset Matematika, 2(1), 39. https://doi.org/10.25157/teorema.v2i1.765 
Asan, A., \& Haliloglu, Z. (2005). Implementing Project Based Learning in Computer Classroom. Turkish Online Journal of Educational Technology-TOJET, 4(3), 68-81.

Asih, I. U. (2019). Analisis statistik deskriptif nilai ujian nasional matematika dan nilai akhir sekolah menengah pertama (smp). Program studi pendidikan matematika jurusan pendidikan mipa fakultas keguruan dan ilmu pendidikan universitas jember, 53(9), 1689-1699. https://doi.org/10.1017/CBO9781107415324.004

Bell, G. E. (1978). A Refinement Of The Heat Balance Integral. 21, 1357-1362.

Berenfeld, B. (1996). Linking students to the infosphere. THE Journal, 23(9), 76-83.

Bodnar, G., \& Hazy, J. (1999). Experiences of project-based teaching applied in the field of psychology. Periodica Polytechnica Social and Management Sciences, 7(2), 173-190.

Cord, O. (2001). Genetic Fuzzy Systems: Evolutionary Tuning And Learning Of Fuzzy Knowledge Bases. Singapore: World Scientific.

Doppelt, Y. (2003a). Implementation and assessment of PjBL in a flexible environment. International Journal of Technology and Design Education, 13(3), 255-272. https://doi.org/10.1023/A:1026125427344

Doppelt, Y. (2003b). Implementation and Assessment of PjBL in a Flexible Environment. International Journal of Technology and Design Education 13, 255-272. Kluwer Academic Publishers. Printed in the Netherlands., 255-272.

Gresham, G. (2010). A Study Exploring Exceptional Education Pre-Service Teachers' Mathematics Anxiety. Issues in the Undergraduate Mathematics Preparation of School Teachers, 4(10), 1-10.

Harususilo, Y. E. (2019). Skor PISA 2018: Daftar Peringkat Kemampuan Matematika, Berapa Rapor Indonesia. Retrieved from Kompas. com.

Kusumah, Y. S. (2017). Inovasi Pembelajaran Matematika Berbasis Multimedia Untuk Meningkatkan Kemampuan Berfikir Matematis Siswa. Prosiding Seminar Nasional Pendidikan Matematika,1(1), 1-18.

Laboy-Rush, D. (2010). Integrated STEM Education through PjBL. STEM Solutions Manager Df. Retrieved from Learning.Com.

Larmer, J. (2014). PjBL vs. problem-based learning vs. X-BL. Buck Institute for Education (BIE).

Marchaim, U. (2001). High-school Student Research at Migal Science Institute in Israel. Journal of Biological Education 1(1), 1-10.

Mergendoller, J. R., \& Thomas, J. W. (2000). Managing project based learning: Principles from the field. Annual Meeting of the American Educational Research Association, 1(1), 1-51.

Molenda, M. (2003). In Search of the Elusive ADDIE Model. Indiana University, 8(1), 89-103. https://doi.org/10.1080/07907189308406510

OECD. (2003). The Programme for International Student Assessment (PISA). PISA Result in Fokus.

OECD. (2006). PISA 2006 Science Competencies for Tomorrow's World. OECD: Executive Summary.

OECD. (2009). The Programme for International Student Assessment (PISA). PISA 2009 Results : Executive Summary.

OECD. (2016). Country Note - Results from PISA 2015: Indonesia. Oecd, 1-8. Retrieved from https://www.oecd.org/pisa/PISA-2015-Indonesia.pdf

Okudan, G. E., \& Rzasa, S. E. (2006). A project-based approach to entrepreneurial leadership education. Technovation, 26(2), 195-210. https://doi.org/10.1016/j.technovation.2004.10.012

Rosenfeld, S., \& Ben-Hur, Y. (2001). PjBL (PBL) in Science and Technology: A Case Study of Professional Development. Israel: Weizmann Institute of Science.

Ruseffendi, E. T. (2006). Pengantar kepada membantu guru mengembangkan kompetensinya dalam pengajaran matematika untuk meningkatkan CBSA. Bandung: Tarsito. 
Schoenfeld, A. H. (1992). Schoenfeld_1992 Learning to Think Mathematically.pdf. Handbook of Research on Mathematics Teaching and Learning, pp. 334-370.

Smith, R. E., Smoll, F. L., Cumming, S. P., \& Grossbard, J. R. (2006). Measurement of multidimensional sport performance anxiety in children and adults: The sport anxiety scale-2. Journal of Sport and Exercise Psychology, 28(4), 479-501. https://doi.org/10.1123/jsep.28.4.479

Stacey, K. (2011). The PISA view of mathematical literacy in Indonesia. Journal on Mathematics Education, 2(2), 95-126. https://doi.org/10.22342/jme.2.2.746.

Suherman, E., \& Kusumah, Y. S. (1990). Petunjuk Praktis Untuk Melaksanakan Evaluasi Pendidikan.

Sun, Y., \& Pyzdrowski, L. (2009). Using technology as a tool to reduce mathematics anxiety. The Journal of Human Resource and Adult Learning, 5(2), 38-44.

Thomas, J. W., Mergendoller, J. R., \& Michaelson, A. (1999). Project based learning for middle school teachers. Middle School Journal, 36(2), 28-31.

Warren Jr, W. H., Rambow, A., Pascarella, J., Michel, K., Schultz, C., \& Marcus, S. (2005). Identifying and Reducing Math Anxiety. In CTLA 704 Workshop.

Yee, \& Hoe. (2009). Teaching Secondary School Mathematics Singapore. McGraw-Hill Education. 